\title{
Investigations of Ultrasonic Vibration Turning
}

\author{
Zhang Jia-Jia ${ }^{1}$,Dai Bang ${ }^{2}$,Huang Tao ${ }^{3}$ \\ (College of Mechanical Engineering, Shanghai University of Engineering Science, Shanghai 201620, P.R.China) \\ Projrct Number: $16 \mathrm{ky} 0122$
}

\begin{abstract}
Ultrasonic vibration (UV) turning is a method with micro-scale high frequency vibration on the cutting tool to make the tool-workpiece interaction a periodically separation and the direction of the friction between tool and chip changed in each cycle of the ultrasonic vibration.The investigations show that the turning efficiency, the micro topography of machined surface can be improved and the ware of cutting tool, the deformation zone in a workpiece can be reduced by the application of the ultrasonic vibration machining. Finite element software simulation are performed on turning in this paper to clarify the advantages of applying tool ultrasonic vibration. The separation-contact process of ultrasonic vibration cutting and compare of ultrasonic vibration cutting force and normal cutting cutting force are studied.
\end{abstract}

Keywords: ultrasonic vibration turning,finite element simulation, cutting force

\section{INTRODUCTION}

The vibration cutting is a new kind of special machining method which gives the tool (or workpiece) an appropriate direction, frequency and amplitude of vibration, to improve the cutting efficiency ${ }^{[1]}$. Compared with ordinary cutting, vibration cutting has a small cutting force, a low cutting heat, high surface quality of the workpiece and better tool endurance which are considered to be an important development direction of mechanical processing ${ }^{[2]}$.

$\mathrm{N}$. Ahmed developed two-dimensional and three-dimensional finite element simulation of vibration cutting, and the cutting force, cutting temperature, the effect of friction coefficient on vibration cutting was analyzed ${ }^{[3]}$. Yang Liang made the single crystal copper precision ultrasonic vibration cutting finite element simulation, studied the stress, cutting temperature distribution ${ }^{[4]}$. Masahiko Jin and Masao Murakawa ${ }^{[5]}$ developed a set of practical ultrasonic vibration cutting tool system which turned the vibration direction from the main cutting direction to the workpiece $10 \sim 30^{\circ}$ for the purpose to prevent the tool from chipping in cutting difficult to process materials. The experimental results showed that the device can effectively prevent the phenomenon of cutting edge wear and obtain good surface quality. Kumabe ${ }^{[6]}$ studied the fundamentals and applications of ultrasonic vibration cutting.

Weber $\mathrm{H}$ et al. ${ }^{[7]}$ carried out the turning of machinable glass ceramics with an ultrasonic vibrated tool. Ahn JH et al. ${ }^{[8]}$ discussed the improvement of micro-machining accuracy by 2-dimensional vibration cutting. A successive micro-channels were shaped using elliptical vibration cutting with varying elliptical cutting paths by Gi Dae Kim and Byoung Gook Loh ${ }^{[9]}$. Nosouhi, $\mathrm{R}^{[10]}$ presented and verified a novel analytical model for prediction of forces in the experimental elliptical vibration-assisted turning tests which used a dynamic friction model.

\section{DESIGN METHOD}

Numerical simulation of the cutting process can provide detailed results for process variables, such as stress, strain, strain rate, temperature, that are extremely difficult to measure with current technology. Owing to advanced technology and computer power, an alternative approach called thearbitrary Lagrangian-Eulerian (ALE) approach ${ }^{[11]}$, which could combine the advantages of Lagrangianand Eulerian approaches, Eliminating meshdistortion in Eulerian formulation and modeling the unconstrained flow of the chip in Lagrangian approach was applied in this research. The ALE approachis proved to be viable once a proper mesh motionscheme been implemented in Fig. 1. 


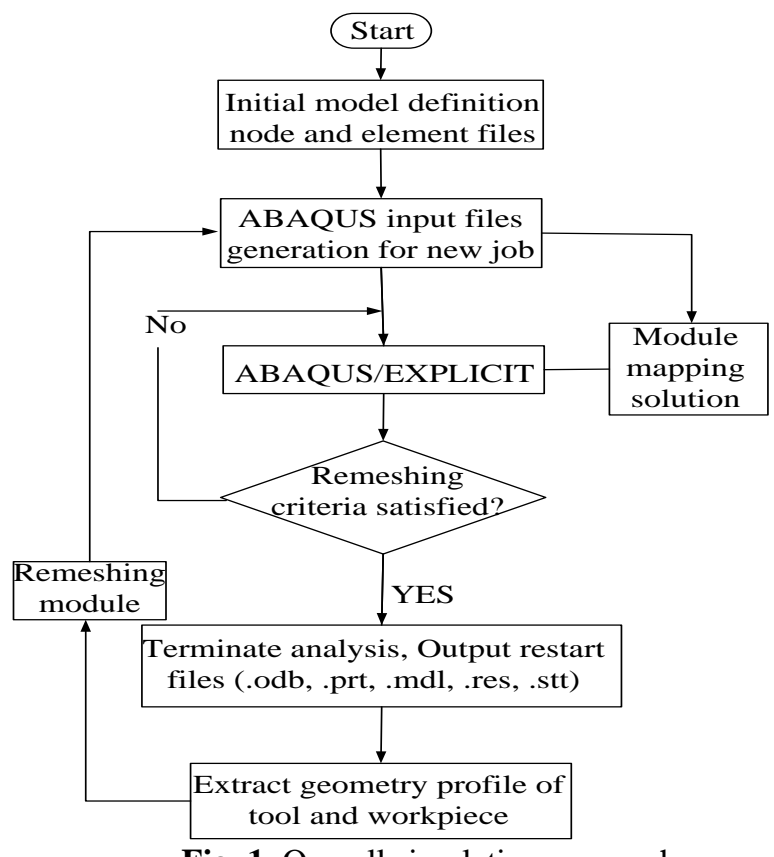

Fig. 1. Overall simulation approach

\section{VIBRATION CUTTING MODEL}

A 2D orthogonal normal cutting model is established in Figu.2 and the vibration cutting simulation model is established in Fig.3. The size of the workpiece is $0.4 \mathrm{~mm} \times 0.12 \mathrm{~mm}$, the cutting thickness is $0.01 \mathrm{~mm}$; the rake angle is $7^{\circ}$, the clearance angle is $7^{\circ}$, and the cutting edge radius is $0.0002 \mathrm{~mm}$. The material of the workpiece is titanium alloy TC4 whose elastic modulus, heat capacity, heat conduction coefficient and the coefficient of linear thermal expansion changing with the temperature respectively. The tool is made of cemented carbide YG8 and adopts rigid body constraints, only the temperature effect is considered, and its deformation is not considered. The parameters of the material are shown in Table 1.

Table 1. Material parameters

\begin{tabular}{|l|l|l|}
\hline Material & $T C 4$ & $Y G 8$ \\
\hline Mass density & $4440 \mathrm{Kg} / \mathrm{m}^{3}$ & $14.5 \mathrm{Kg} / \mathrm{m} 3$ \\
\hline Specific heat & $611 \mathrm{~J} / \mathrm{kg} \cdot{ }^{\circ} \mathrm{C}$ & $220 \mathrm{~J} / \mathrm{kg} \cdot{ }^{\circ} \mathrm{C}$ \\
\hline Conductivity & $6.8 \mathrm{~W} / \mathrm{m} \cdot \mathrm{k}$ & $75.4 \mathrm{~W} / \mathrm{m} \cdot \mathrm{k}$ \\
\hline Young's modulus & $1.09 \mathrm{E}+05 \mathrm{MPa}$ & $6.4 \mathrm{E}+05 \mathrm{MPa}$ \\
\hline Poisson ratio & 0.34 & 0.22 \\
\hline
\end{tabular}

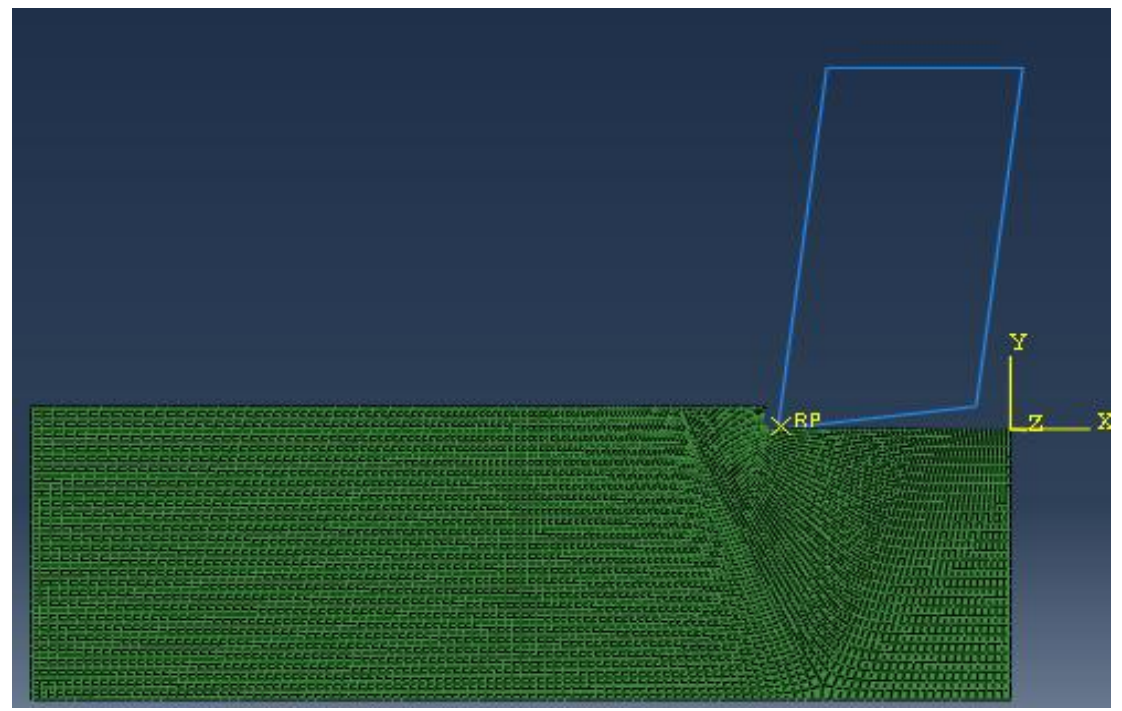

Fig. 2. Contact between the workpiece and tool in normal cutting model 


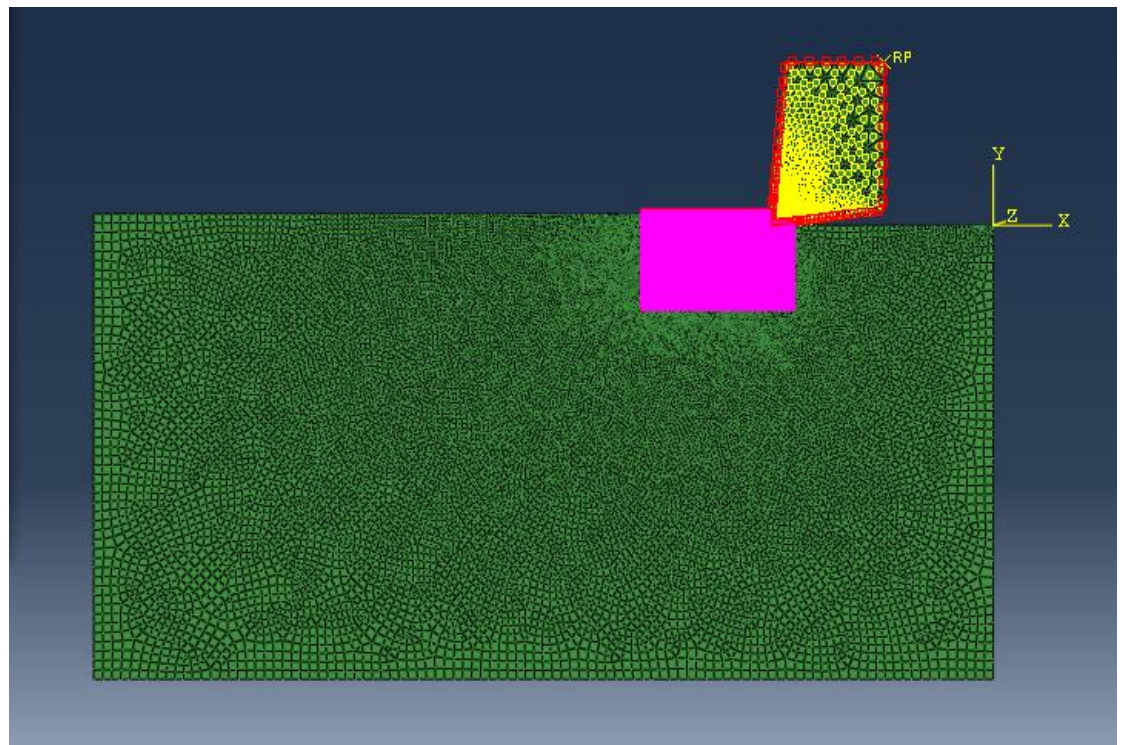

Fig. 3. Contact between the workpiece and tool in ultrasonic vibration cutting model

\subsection{Cutting process}

\section{SIMULATION RESULTS}

This paper realized vibration cutting simulation. According to the vibration cutting cycle of the tool, the process can be divided into three main stages: the first stage is before the cutting where the tool separated with workpiece; the second stage is the cutting process, the tool cutting into the workpiee; the final stage is the unloading process, chip separated with the tool. The separation-cutting-separation cycle in vibration cutting is shown in Fig 4(a), (b), (c).

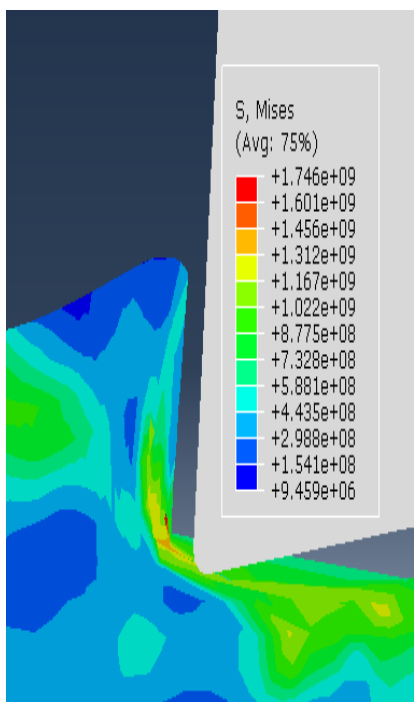

(a)separation

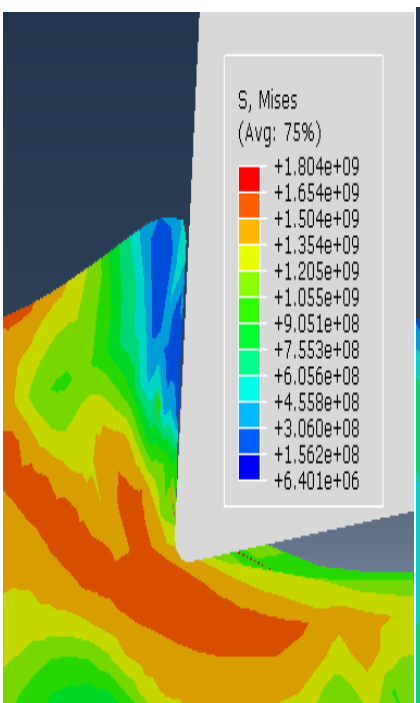

(b) cutting

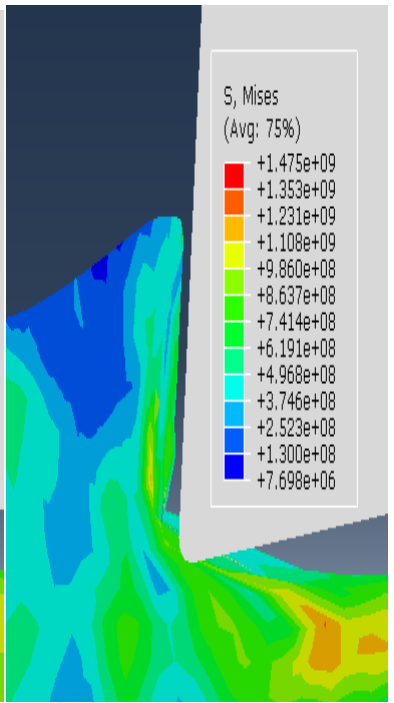

(c) separation

Fig.4. Tangential vibration cutting process

\subsection{Cutting force}

In ordinary cutting, the cutting tool and the workpiece are always in contact, cutting force increase with the tool's cutting into the workpiece. The cutting force reaches the maximum value when the cutting being in the steady state and maintain the fluctuations in this value. In the process of ultrasonic vibration cutting tool-chip is a process of constant contact and separation and there are quite a long time the tool is separated from the chip in the process of ultrasonic vibration turning, thus the cutting force is small at this time. Chip separates from tool when it meets the need of separation standard of the ultrasonic vibration, gradually cutting force are suddenly smaller. While in the ordinary turning the tool is contacting with the chip all the time. It is obviously that the ultrasonic vibration turning can significantly reduce the cutting force, as shown in Fig 5. 


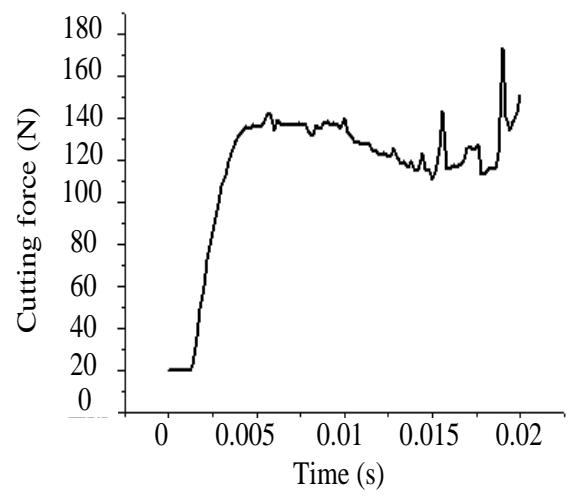

(a)Vibration cutting force

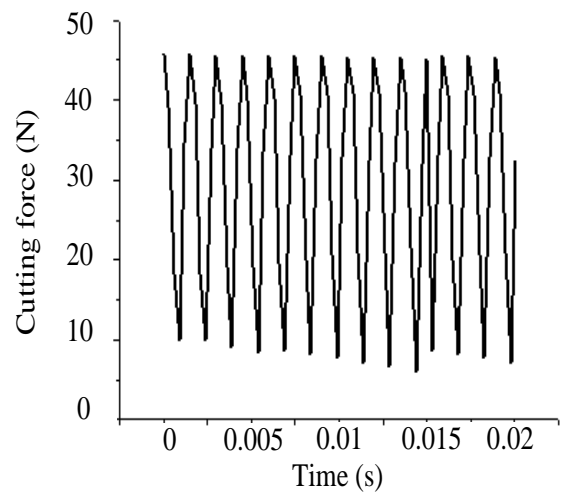

(b) Normal cutting force

Fig.5. Cutting force

\section{CONCLUSION}

The ultrasonic vibration cutting technology is a promising special processing technology, has its unique advantages in cutting of difficult machining materials. In this paper the essential difference with the traditional ultrasonic vibration turning turning process, analysis from the angle of the ultrasonic vibration cutting mechanism of the cutting process. On this basis, the establishment of simulation of two-dimensional cutting model using Abaqus/Explicit finite element to carry out numerical simulation software, the traditional cutting and ultrasonic vibration cutting. In addition, the prediction of the cutting force of traditional turning and ultrasonic vibration turning using simulation model. The numerical simulation proved that the ultrasonic vibration cutting can reduce the cutting force.

\section{ACKNOLEDGEMENT}

This project is sponsored by Shanghai University of Engineering Science Innovation Fund for Graduate Students (No. 16KY0122).

\section{REFERENCE}

[1]. A. Schubert, A. Nestler, S. Pinternagel, H. Zeidler. Influence of ultrasonic vibration assistance on the surface integrity in turning of the aluminium alloy AA2017 [J]. Mat.-wiss. U. Werkstofftech.2011,42(7):658-665.

[2]. Xun Li, Deyuan Zhang. Ultrasonic elliptical vibration transducer driven by single actuator and its application in precision cutting[J].Journal of Materials Processing Technology, 2006,180:91-95

[3]. Ahmed Syed Adnan, Sathyan Subbiah. Experimental investigation of transverse vibration assisted orthogonal cutting of AL-2024 [J]. International Journal of Machine Tools \& Manufacture.2010,50:294-302.

[4]. Yang Liang, Lu Zesheng. Influence of amplitude on the precision ultrasonic vibration cutting dimension error of workpiece[J]. manufacturing technology and machine tool, 2007,3:92-96.

[5]. Masahiko Jin, Masao Murakawa. Development of a practical ultrasonic vibration cutting tool system[J]. Journal of Materials Processing Technology,2001,113:342-347.

[6]. Kumabe J (1979) Fundamentals and applications: ultrasonic cutting. Jikkyou Publishing Co., 1979

[7]. Weber H, Herberger J, Pilz R (1984) Turning of machinable glass ceramics with an ultrasonically vibrated tool. CIRP Ann 33:85-87

[8]. Ahn JH, Lim HS, Son SM (1999) Improvement of micro-machining accuracy by 2-dimensional vibration cutting. In: Proceedings of the fourteenth annual meeting of the ASPE, pp 150-153.

[9]. Kim GD, Loh BG (2010) Machining of micro-channels and pyramid patterns using elliptical vibration cutting. Int J Adv Manuf Technol 49:961-968

[10]. Nosouhi R, Behbahani S, Amini S et al (2013) Experimental and analytical study of the elliptical vibration-assisted turning process with the dynamic friction model. Proc Inst Mech Eng Part B: J Eng Manuf 0954405413508943:1-10

[11]. Al-Athel, K.S., Gadala, M.S. (2011). The use of volume of solid (VOS) approach in simulating metal cutting with chamfered and blunt tools. International Journal of Mechanical Sciences, vol. 53, no. 1, p. 23-30,DOI:10.1016/j.ijmecsci.2010.10.003. 